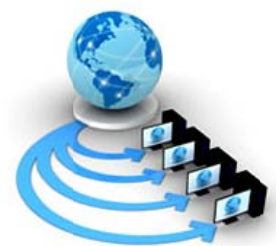

\author{
Available Online at www.ijarcs.info
}

\title{
IMPACT OF DISTANCE METRICS ON THE PERFORMANCE OF K-MEANS AND FUZZY C-MEANS CLUSTERING - AN APPROACH TO ASSESS STUDENT'S PERFORMANCE IN E-LEARNING ENVIRONMENT
}

\author{
V.P. Mahatme \\ Department of Computer Technology \\ Kavikulguru Institute of Technology \& Science, Ramtek, \\ Dist:Nagpur, (MS), India
}

\author{
Dr. K.K. Bhoyar \\ Department of Information Technology \\ Yeshwantrao Chavan College of Engineering, \\ Nagpur, Dist:Nagpur, (MS), India
}

\begin{abstract}
Data clustering has many applications in the various research areas. In clustering algorithm, distance metrics is a key constitute in finding regularities in the data objects. Mostly distance based metrics are used as similarity measures in clustering. Distance metrics do not always perform better. Distance metric does not exhibit well in capturing correlations among the data objects. Choosing the right distance metric for a given dataset is a great challenge. In this paper, impact of three different metrics Euclidean, Manhattan and Pearson correlation coefficient on the performance of k-means and fuzzy c-means clustering is presented. In clustering, detection of similarity using distance metrics affects the accuracy of the algorithm. This study helps the researchers to take quick decision about choice of metric for clustering.
\end{abstract}

Keywords: data mining; k-means clustering; fuzzy c-means clustering; distance metrics; e-learning

\section{INTRODUCTION}

Now-a-days data is increasing in exponential rate. Generated data is of high dimensionality. Appropriate data analysis of such data is very much important. There are various supervised and unsupervised data mining techniques exist for this purpose. In data mining techniques, concept of regularity or similarity is carrying attention of researchers to discover in what way data are interrelated, how they are similar or different. Among various data mining task, clustering is popularly being used to get the insight of data. In clustering data objects are grouped together using similarity measure. Most commonly used distance metrics for similarity measure are Euclidian distance, Manhattan distance, Chebyshev distance, Minkowski distance. It is always remain question in mind that which metric is more appropriate. In this research, study is carried out to analyze the student's interest in use of programming tools, social networking, internet surfing for casual usage and e-learning activities for course studies. In the present paper, the impact of Euclidian distance, Manhattan distance and Pearson correlation coefficient on the performance of K-Means (KM) and Fuzzy C-Means (FCM) clustering algorithms has been studied and presented.

\section{RELATED WORK}

This section reviewed earlier work in clustering and uses of various distance metrics. Aha K. D. et. al.[1] described overlap metric. Instance based learning and locally weighted learning are mostly used overlap metric. It does not use additional information given by nominal attribute values. So, it is a rough measure. Standfill C. et. al.[2] proposed value difference metric. It is presumed that attribute are closer if they have more similar classifications. Their results showed that value difference metric is more precise than overlap metric. Daniel Tunkelang et.al.[3] showed data driven difference measure specifically for categorical data.
Difference between two data objects depends on the frequency of the categories or combinations of categories that data objects have in common. Xu R. [4] reviewed that there is no clustering algorithm that can be commonly used across all problems. Further, they claimed that in the context of clustering, it is difficult to say that it is the best clustering. Generally, algorithms are designed with certain assumptions and favor some type of biases. Distance metrics for nominal attributes reviewed by Chaoqm Li. et. al.[5]. They used 36 UCI datasets of Weka platform and suggested improvements based on attribute weighting and attribute selection. Chaoqun Li [6] used attribute selection approach and suggested Selective Value Difference Metric (SVDM). They investigated the attribute independence assumption of Value Difference Metric and then presented two effective attribute selection methods for SVDM. Peter Grabusts[7] used three metrics Euclidian, Manhattan and correlation in hierarchical clustering method. They obtained similar result by applying all three metrics. They suggested that accuracy of algorithm depends on the complexity of task and data size. Performance of six distance metrics on k-means, single linkage and average linkage clustering algorithms are examined by Kumar V.et.al. [8]. To assess the performance of clustering they referred Euclidean, Euclidean squared, Manhattan, Mahalanobis, cosine similarity and Pearson correlation distance metrics. Anil kumar Patidar [9] presented the impact of four similarity measures on Shared Nearest Neighbor clustering. Their analysis showed that Euclidean distance function works best with Shared Nearest Neighbor clustering approach in contrast to cosine, Jaccard and correlation distance measures function. Jasmine Irani et. al.[10] reviewed various distance based clustering techniques and expressed the limitations of the existing clustering techniques. To overcome this they proposed combination model of clustering. 


\section{DATA MINING}

Data mining process helps to automatically understand process and summarize high dimensional data. This extract novel, valid, useful knowledge patterns from large data sets [11]. In fact, data mining is one step in the process of Knowledge Discovery from Database (KDD). KDD process is given in figure 1.

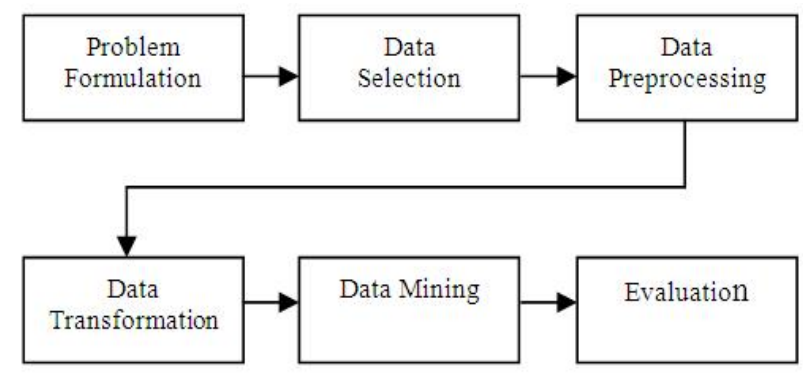

Figure 1. KDD Process

Following steps are required for KDD process.

- Data selection: In this step, relevant information from database is selected.

- Data pre-processing: This is the process of identification and elimination of missing, inaccurate, noisy and duplicate data value from the data set.

- Data transformation: In this process, data are transformed into correct form to perform different operations like summary, aggregation, generalization and normalized operation.

- Data mining: It is a technique through which various descriptive and predictive operations perform on the data to extract the hidden knowledge.

- Evaluation: In this step, extracted knowledge is evaluated.

There are two types of goals for in data mining process.

\section{A. Descriptive Mining}

Descriptive mining recognize the relationship or dependencies among the data objects.

\section{B. Predictive Mining}

Predictive mining creates a model of future behavior based on the current available data.

\section{DATA CLUSTERING}

Data clustering discover semantically meaningful group of data objects. Given a dataset, clustering divide data objects based on similarity measures which follow two important criterions that the similarity between any two data objects within a group is maximized and the similarity between any two data objects within any two groups is minimized. Clustering is used by the researchers of any domain who wish to process data. Domain varies from social studies, engineering, computing, medical and so on. Data clustering is also called as Q-analysis, clumping and taxonomy depending on the domain where it is used [12]. Clustering roughly categorized into two groups viz. partition clustering and hierarchical clustering. Partition clustering algorithm partitioned data into appropriate clusters whereas hierarchical clustering is recursively finds nested clusters. Hierarchical clustering either works in bottom-up or in top-down manner which is called as agglomerative or divisive algorithm respectively. The most popular and the simplest partition algorithm is k-mean clustering. It is a simple, scalable, easily understandable and can be adopted to deal with high dimensional data. It is unsupervised learning, used when data is unlabeled.

\section{K-means clustering}

It is a partition based clustering method. Basic intension of this is to categorize given data set into k clusters. Given algorithm shows the process of k-means clustering. It follows iterative refinement method. The process starts with randomly generated initial $\mathrm{k}$ centroids from the data set then iterates between two steps: 'Data assignment' and 'Centroids update'.

- Data assignment: Each centroid defines one of the clusters. Based on the distance function data objects are assigned to its nearest centroid.

- Centroid update: Centroids are recalculated by taking the mean of all data objects assigned to the respective centroid's cluster.

The algorithm iterates between these two steps until convergence criteria is met. Convergence criteria may be one of the following.

- No data object change clusters.

- Sum of the distances is minimized.

- Maximum number of iterations is reached. Algorithm

1. Initialization of number of clusters.

2. Initialization of cluster centers.

3. Repeat

Assign each item to the cluster which has the closest centroid;

Calculate new mean for each cluster; Until convergence criteria is met.

\section{Fuzzy c-means clustering}

In machine learning, blending of fuzzy logic and data mining is extensively used. Non-unique partitioning of the data objects in cluster formation is the key in fuzzy clustering. Data objects are assigned with a membership value for each of the clusters. It designates the proximity of the data object to a particular cluster. It is the most popular classical fuzzy clustering technique. Major domains such as image analysis, medical diagnosis, astronomy, chemistry and agricultural where fuzzy c-means clustering are widely used [13]. Fuzzy c-means clustering has two phases. In the first phase, cluster centers are calculated and in the second phase data objects are assigned to these clusters using a membership value as distance measure. This process repeats until the cluster centers become stable. For each data object, there is a coefficient that specifies the membership degree $\left(\mu_{\mathrm{ij}}\right)$ of being in the $\mathrm{k}^{\text {th }}$ cluster as follows.

$$
\mu_{i j}=\sum_{k=1}^{n}\left(d_{i j} / d_{i k}\right)^{\left(2 / m^{-1}\right)}
$$

Where,

$\mathrm{d}_{\mathrm{ij}}$ : distance of $\mathrm{i}^{\text {th }}$ item from $\mathrm{j}^{\text {th }}$ cluster

$\mathrm{d}_{\mathrm{ik}}$ : distance of $\mathrm{i}^{\text {th }}$ item from $\mathrm{k}^{\text {th }}$ cluster

$\mathrm{m}$ : fuzzification factor 
The presence of a data object in multiple cluster depends on the fuzzification value say ' $m$ ' which is defined by the user in the range of [0,1]. It decides the fuzzy membership degree in the cluster. Data object which is on the boundary of cluster might be in that cluster with lesser membership degree than other data object in the center of the cluster [14][15]. Whenever ' $m$ ' reaches the value of 1 the algorithm works like a crisp partitioning algorithm. The principle goal of fuzzy clustering algorithm is to segment the data objects into clusters so that the intra-cluster similarity of data objects is boosted and the inter-cluster similarity of data objects is minimized.

\section{Algorithm}

1. Initialize number of clusters.

2. Initialize fuzzification parameter.

3. Initialize cluster centers.

4. Repeat

Update membership of data point,

Update center of the cluster with current membership of data point,

Until cluster centers estimate stabilize.

\section{NEED OF DISTANCE METRICS IN CLUSTERING}

Clustering is based on a similarity measure to group data objects together [16]. Similarity is a standard unit to express closeness of two data objects. Distance metric is a most widely used technique to quantify the similarity among the data objects. Distance metric specifies how the distance between two data objects is measured. In many of the applications, Euclidean distance, Manhattan distance, Minkowski distance are used. K-means clustering and fuzzy c-means clustering are unsupervised learning. Clustering results of these algorithms may be affected by several parameters such as algorithm initialization, distance metric, data size and so on. So, it is worth to evaluate the impact of distance metrics on k-means and fuzzy c-means algorithms in clustering data. This paper is aimed to analyze the impact distance metrics such as Euclidean distance, Manhattan distance and Pearson correlation coefficient in k-means and fuzzy c-means clustering algorithms. Various distance metrics are reviewed below.

- Euclidean distance: In clustering task, Euclidean distance is commonly used. Basically, it is geometrical distance between two points. The Euclidean distance calculates the root of square differences between the coordinates of objects pair [9]. It is shown in equation 2.

$$
\operatorname{Dist}_{X Y}=\sqrt{\sum_{k=1}^{m}\left(X_{i k}-X_{j k}\right)^{2}}
$$

- Manhattan distance: Manhattan distance calculates the absolute differences between coordinates of objects pair [10]. It is shown in equation 3.

$$
\operatorname{Dist}_{X Y}=\left|X_{i k}-X_{j k}\right|
$$

- Chebyshev distance: Chebyshev distance is maximum value distance. This compute the absolute magnitude of the differences between coordinate of objects pair [10] as given in equation 4.

$$
\operatorname{Dist}_{X Y}=\max _{k}\left|X_{i k}-X_{j k}\right|
$$

- Minkowski distance: Minkowski distance is generalized distance metric [10]. It is given in equation 5.

$$
\operatorname{Dist}_{X Y}=\left(\sum_{k=1}^{d}\left|X_{i k}-X_{j k}\right|^{\frac{1}{P}}\right)^{P}
$$

When $\mathrm{p}=2$, the distance becomes the Euclidean distance. When $\mathrm{p}=1$ it becomes Manhattan distance.

- Pearson correlation coefficient: This distance depends on the Pearson correlation coefficient. This is calculated from the sample values and their standard deviations. It shows the closeness between two continuous variables [17]. The correlation coefficient ' $r$ ' takes values from +1 to -1 . It is given in equation 6 . A value of 0 indicates that there is no association between the two variables. A value greater than 0 indicates a positive association. Effectively, Pearson distance ' $d_{p}$ ' is computed as $d_{p}=1-r$ as shown in equation 7. It lies between 0 and 2. 0 when correlation coefficient is +1 , i.e. the two samples are most similar and 2 when correlation coefficient is $-1[7]$.

$$
\begin{gathered}
r_{X Y}=\frac{\sum_{t=1}^{n}\left(X_{i}-\bar{X}\right)\left(Y_{i}-\bar{Y}\right)}{\sqrt{\sum_{i=1}^{n}\left(X_{i}-X\right)^{2} \sqrt{\sum_{i=1}^{n}\left(Y_{i}-Y\right)^{2}}}} \\
d_{p}(X, Y)=1-r_{X Y}
\end{gathered}
$$

\section{EXPERIMENTAL DESIGN}

Proposed work involved application of data mining technique specifically K-Means (KM) and Fuzzy C-Means (FCM) clustering and to study the impact of distance metrics on the performance of these algorithms. Experimentation is carried out which include following steps.

\section{E. Data Gathering}

In this experiment, data set consists of review questions for illustration purpose. There were 28 questions in the data set which were attempted by 54 students. Questions were set to finds the student's interest in the various activities such as social networking, use of programming tools, internet surfing for casual usage and referring e-learning resources for course study. Questions were of multiple choice and text formatted. If student response to question is positive, then it was graded by 1 . It is 0 otherwise. If student didn't answer the question then it was graded by 0 . All required data for this research work is collected from Moodle log file through Moodle server. Collected log data was used for preprocessing. Basically, intension of the preprocessing is to cleanse the data and to transform it into a suitable form so that it will be used in later stages. Preprocessed data set consist of questions and student's response.

\section{F. Methodology}

Experiment follows the methodology as mentioned in figure 2. The pre-processing phase is an important phase in any system that uses a data mining framework. All questions in the system were undergone through pre-processing phase 
before clustering, Later it must be transformed into a simpler form which acts as an input to the clustering algorithm [18][19]. Clustering algorithm have tendency to discover natural grouping of data objects based on some similarity. It also finds the centroid of a group of data objects. Data clustering has been used mainly for three purposes: underlying structure, natural classification and compression. Later, clustering result is validated by identifying correctness of the clusters.

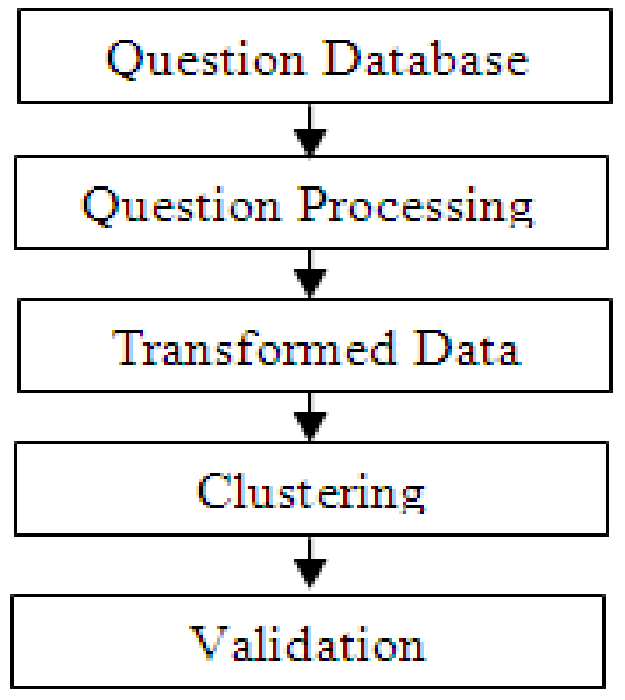

Figure 2. Proposed Methodology

\section{EXPERIMENTAL RESULTS}

The purpose of the experiment was to test the performance of the KM and FCM clustering algorithms by applying three different metrics. Euclidean distance, Manhattan distance and Pearson correlation coefficient have been selected as metrics. Preprocessed data set was grouped into four clusters by applying KM and FCM clustering with three different distance metrics. Basically, in this research, student's interest in social networking, programming tools, internet surfing for casual usage and referring e-learning resources for course study have been considered. Clustering result and group of students in each cluster with k-means are shown in tables 1, 2, 3 and with fuzzy c-means shown in table 4, 5, 6 .

Table I. K-means Clustering with Euclidian Distance

\begin{tabular}{|c|c|c|c|c|c|}
\hline Cluster & \multicolumn{4}{|c|}{ Dimension's Centroid } & \multirow{2}{*}{$\begin{array}{c}\text { No. of } \\
\text { students }\end{array}$} \\
\cline { 2 - 5 } & $\begin{array}{c}\text { Programming } \\
\text { tools }\end{array}$ & $\begin{array}{c}\text { Social } \\
\text { networkin } \\
\text { g }\end{array}$ & $\begin{array}{c}\text { Internet } \\
\text { surffing } \\
\text { for } \\
\text { casual } \\
\text { usage }\end{array}$ & $\begin{array}{c}\text { E- } \\
\text { learning } \\
\text { activities } \\
\text { for } \\
\text { course } \\
\text { study }\end{array}$ & \\
\hline C1 & 0.669 & 0.80 & 0.60 & 0.286 & 14 \\
\hline C2 & 0.642 & 0.64 & 1.00 & 0.453 & 20 \\
\hline C3 & 0.902 & 0.94 & 0.98 & 0.649 & 10 \\
\hline C4 & 0.646 & 0.91 & 0.82 & 0.771 & 10 \\
\hline
\end{tabular}

Table II. K-Means Clustering with Manhatton Distance \begin{tabular}{|c|c|c|}
\hline Cluster & Dimension's centroid & No. of \\
\hline
\end{tabular}

\begin{tabular}{|c|c|c|c|c|c|}
\hline & $\begin{array}{c}\text { Programming } \\
\text { tools }\end{array}$ & $\begin{array}{c}\text { Social } \\
\text { networkin } \\
\mathrm{g}\end{array}$ & $\begin{array}{c}\text { Internet } \\
\text { surffing } \\
\text { for } \\
\text { casual } \\
\text { usage }\end{array}$ & $\begin{array}{c}\text { E- } \\
\text { learning } \\
\text { activities } \\
\text { for } \\
\text { course } \\
\text { study }\end{array}$ & students \\
\hline C1 & 0.818 & 0.952 & 1.00 & 0.704 & 14 \\
\hline C2 & 0.643 & 0.636 & 1.00 & 0.428 & 22 \\
\hline C3 & 0.569 & 0.733 & 0.45 & 0.285 & 05 \\
\hline C4 & 0.723 & 0.846 & 0.75 & 0.571 & 13 \\
\hline
\end{tabular}

Table III. K-means Clustering with Pearson Correlation Coefficient

\begin{tabular}{|c|c|c|c|c|c|}
\hline Cluster & \multicolumn{4}{|c|}{ Dimension's centroid } & $\begin{array}{c}\text { No. of } \\
\text { students }\end{array}$ \\
\cline { 2 - 5 } & $\begin{array}{c}\text { Programmin } \\
\text { g tools }\end{array}$ & $\begin{array}{c}\text { Social } \\
\text { networkin } \\
\text { g }\end{array}$ & $\begin{array}{c}\text { Internet } \\
\text { surffing } \\
\text { for } \\
\text { casual } \\
\text { usage }\end{array}$ & $\begin{array}{c}\text { E- } \\
\text { learnin } \\
\text { g } \\
\text { activitie } \\
\text { s for } \\
\text { course } \\
\text { study }\end{array}$ & \\
\hline C1 & 0.825 & 0.889 & 0.82 & 0.457 & 15 \\
\hline C2 & 0.678 & 0.575 & 0.97 & 0.467 & 22 \\
\hline C3 & 0.607 & 1.00 & 0.82 & 0.449 & 10 \\
\hline C4 & 0.637 & 0.857 & 0.89 & 0.857 & 07 \\
\hline
\end{tabular}

Table IV. FCM Clustering with Euclidian Distance

\begin{tabular}{|c|c|c|c|c|c|}
\hline \multirow[t]{2}{*}{ Cluster } & \multicolumn{4}{|c|}{ Dimension's centroid } & \multirow{2}{*}{$\begin{array}{c}\text { No. of } \\
\text { student } \\
\text { s }\end{array}$} \\
\hline & $\begin{array}{c}\text { Programming } \\
\text { tools }\end{array}$ & $\begin{array}{c}\text { Social } \\
\text { networkin } \\
\mathrm{g}\end{array}$ & $\begin{array}{c}\text { Internet } \\
\text { surffing } \\
\text { for } \\
\text { casual } \\
\text { usage }\end{array}$ & $\begin{array}{c}\text { E- } \\
\text { learning } \\
\text { activities } \\
\text { for } \\
\text { course } \\
\text { study }\end{array}$ & \\
\hline $\mathrm{C} 1$ & 0.669 & 0.80 & 0.60 & 0.286 & 10 \\
\hline $\mathrm{C} 2$ & 0.642 & 0.64 & 1.00 & 0.453 & 23 \\
\hline$\overline{\mathrm{C} 3}$ & 0.902 & 0.94 & 0.98 & 0.649 & 11 \\
\hline C4 & 0.646 & 0.91 & 0.82 & 0.771 & 10 \\
\hline
\end{tabular}

Table V. FCM Clustering with Manhatton Distance

\begin{tabular}{|c|c|c|c|c|c|}
\hline Cluster & \multicolumn{4}{|c|}{ Dimension's centroid } & \multirow{2}{*}{$\begin{array}{c}\text { No. of } \\
\text { students }\end{array}$} \\
\cline { 2 - 5 } & $\begin{array}{c}\text { Programming } \\
\text { tools }\end{array}$ & $\begin{array}{c}\text { Social } \\
\text { networkin } \\
\mathrm{g}\end{array}$ & $\begin{array}{c}\text { Internet } \\
\text { surffin } \\
\text { g for } \\
\text { casual } \\
\text { usage }\end{array}$ & $\begin{array}{c}\text { E- } \\
\text { learning } \\
\text { activities } \\
\text { for } \\
\text { course } \\
\text { study }\end{array}$ & \\
\hline C1 & 0.572 & 0.67 & 1.00 & 0.412 & 16 \\
\hline C2 & 0.603 & 0.73 & 0.50 & 0.286 & 06 \\
\hline C3 & 0.838 & 0.80 & 0.94 & 0.514 & 20 \\
\hline C4 & 0.692 & 0.92 & 0.85 & 0.798 & 12 \\
\hline
\end{tabular}

Table VI. FCM Clustering with Pearson Correlation Coefficient

\begin{tabular}{|c|c|c|}
\hline Cluster & Dimension's centroid & $\begin{array}{c}\text { No. of } \\
\text { students }\end{array}$ \\
\hline
\end{tabular}




\begin{tabular}{|c|c|c|c|c|c|}
\hline & $\begin{array}{c}\text { Programming } \\
\text { tools }\end{array}$ & $\begin{array}{c}\text { Social } \\
\text { networking }\end{array}$ & $\begin{array}{c}\text { Internet } \\
\text { surffin } \\
\text { g for } \\
\text { casual } \\
\text { usage }\end{array}$ & $\begin{array}{c}\text { E- } \\
\text { learning } \\
\text { activities } \\
\text { for } \\
\text { course } \\
\text { study }\end{array}$ & \\
\hline C1 & 0.604 & 0.976 & 0.91 & 0.612 & 14 \\
\hline C2 & 0.636 & 0.515 & 0.89 & 0.662 & 11 \\
\hline C3 & 0.722 & 0.641 & 1.00 & 0.385 & 13 \\
\hline C4 & 0.813 & 0.896 & 0.78 & 0.455 & 16 \\
\hline
\end{tabular}

metrics. Traditionally Euclidian metric is being used but choice of the Pearson correlation coefficient distance metric proved to be better.

Result shows that grouping of students varies with different distance metric in both K-means and FCM clustering. In the presented work, to see the impact of metrics, correctness of four clusters has been analyzed. Cluster correctness using K-means algorithm is shown in table 7 and depicted in figure 3 . Result shows that data set are correctly classified in four clusters using Manhattan and Pearson correlation coefficient distance metric. Whereas with Euclidian distance, cluster 3 and cluster 4 are correctly classified but correctness of cluster 1 and cluster 2 using Euclidian distance is $85.71 \%$ and $95 \%$ respectively. Further, cluster correctness using Fuzzy c-means clustering algorithm is shown in table 8 and depicted in figure 4 . It shows that in FCM, data set is correctly classified in four clusters using Pearson correlation coefficient distance metric. Whereas with Euclidian distance cluster 1, cluster 2, cluster 4 are correctly classified and correctness of cluster 3 is $90.9 \%$.With Manhattan distance, cluster 1 , cluster 2, cluster 4 are correctly classified and correctness of cluster 3 is $90 \%$. From this, it is concluded that Pearson correlation coefficient distance metric performs best in both K-means and Fuzzy cmeans clustering algorithms compared to other two distance

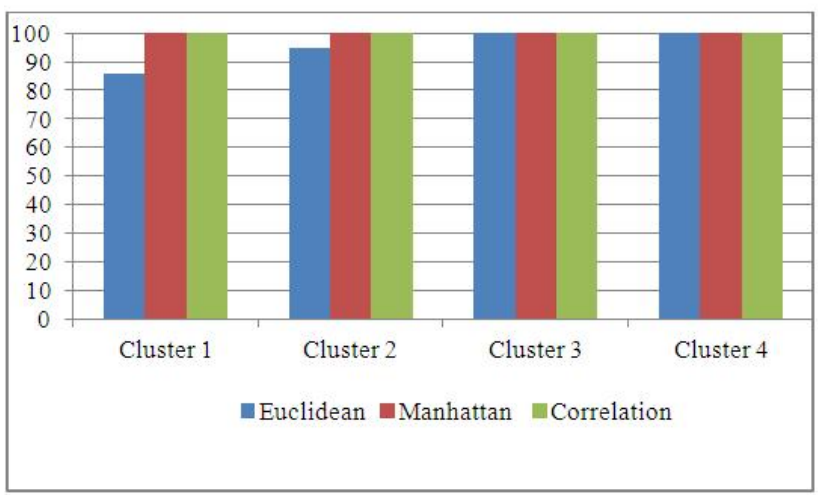

Figure 3. Cluster accuracy using K-means clustering

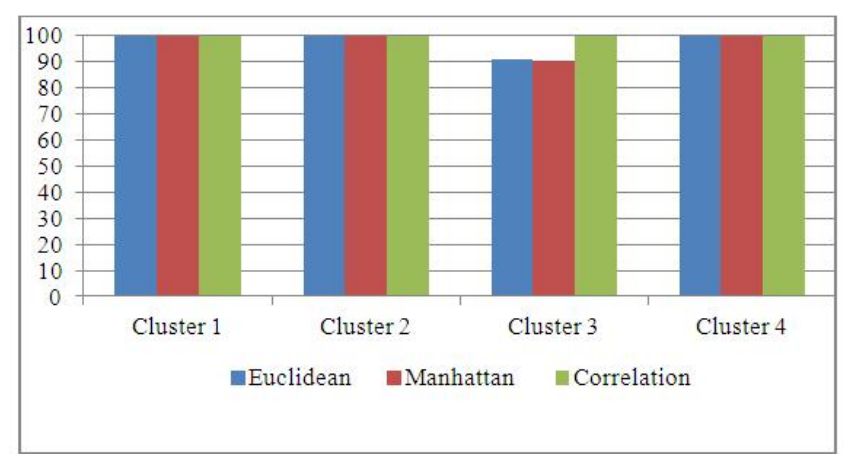

Figure 4. Cluster accuracy using Fuzzy c-means clustering

Table VII. Potentiality of Distance Metric in K-Means Clustering

\begin{tabular}{|c|c|c|c|}
\hline & Euclidean & Manhattan & $\begin{array}{c}\text { Pearson correlation } \\
\text { coefficient }\end{array}$ \\
\hline $\begin{array}{l}\text { Cluster } 1 \\
\text { Contains }\end{array}$ & $\begin{array}{l}\text { Records from cluster } 1=12 \\
\text { Records from cluster } 2=1 \\
\text { Records from cluster } 3=0 \\
\text { Records from cluster } 4=1\end{array}$ & $\begin{array}{l}\text { Records from cluster } 1=14 \\
\text { Records from cluster } 2=0 \\
\text { Records from cluster } 3=0 \\
\text { Records from cluster } 4=0\end{array}$ & $\begin{array}{l}\text { Records from cluster } 1=15 \\
\text { Records from cluster } 2=0 \\
\text { Records from cluster } 3=0 \\
\text { Records from cluster } 4=0\end{array}$ \\
\hline $\begin{array}{l}\text { Cluster } 2 \\
\text { Contains }\end{array}$ & $\begin{array}{l}\text { Records from cluster } 1=1 \\
\text { Records from cluster } 2=19 \\
\text { Records from cluster } 3=0 \\
\text { Records from cluster } 4=0\end{array}$ & $\begin{array}{l}\text { Records from cluster } 1=0 \\
\text { Records from cluster } 2=22 \\
\text { Records from cluster } 3=0 \\
\text { Records from cluster } 4=0\end{array}$ & $\begin{array}{l}\text { Records from cluster } 1=0 \\
\text { Records from cluster } 2=22 \\
\text { Records from cluster } 3=0 \\
\text { Records from cluster } 4=0\end{array}$ \\
\hline $\begin{array}{l}\text { Cluster } 3 \\
\text { Contains }\end{array}$ & $\begin{array}{l}\text { Records from cluster } 1=0 \\
\text { Records from cluster } 2=0 \\
\text { Records from cluster } 3=10 \\
\text { Records from cluster } 4=0\end{array}$ & $\begin{array}{l}\text { Records from cluster } 1=0 \\
\text { Records from cluster } 2=0 \\
\text { Records from cluster } 3=5 \\
\text { Records from cluster } 4=0\end{array}$ & $\begin{array}{l}\text { Records from cluster } 1=0 \\
\text { Records from cluster } 2=0 \\
\text { Records from cluster } 3=10 \\
\text { Records from cluster } 4=0\end{array}$ \\
\hline $\begin{array}{l}\text { Cluster } 4 \\
\text { Contains }\end{array}$ & $\begin{array}{l}\text { Records from cluster } 1=0 \\
\text { Records from cluster } 2=0 \\
\text { Records from cluster } 3=0 \\
\text { Records from cluster } 2=10\end{array}$ & $\begin{array}{l}\text { Records from cluster } 1=0 \\
\text { Records from cluster } 2=0 \\
\text { Records from cluster } 3=0 \\
\text { Records from cluster } 4=13\end{array}$ & $\begin{array}{l}\text { Records from cluster } 1=0 \\
\text { Records from cluster } 2=0 \\
\text { Records from cluster } 3=0 \\
\text { Records from cluster } 4=7\end{array}$ \\
\hline Correctness & $\begin{array}{l}\text { Cluster } 1=85.71 \% \\
\text { Cluster } 2=95 \% \\
\text { Cluster } 3=100 \% \\
\text { Cluster } 4=100 \%\end{array}$ & $\begin{array}{l}\text { Cluster } 1=100 \% \\
\text { Cluster } 2=100 \% \\
\text { Cluster } 3=100 \% \\
\text { Cluster } 4=100 \%\end{array}$ & $\begin{array}{l}\text { Cluster } 1=100 \% \\
\text { Cluster } 2=100 \% \\
\text { Cluster } 3=100 \% \\
\text { Cluster } 4=100 \%\end{array}$ \\
\hline
\end{tabular}

Table VIII. Potentiality of Distance Metric in Fuzzy C-means Clustering

\begin{tabular}{|c|c|c|c|}
\hline & Euclidean & Manhattan & $\begin{array}{c}\text { Pearson correlation } \\
\text { coefficient }\end{array}$ \\
\hline $\begin{array}{l}\text { Cluster } 1 \\
\text { Contains }\end{array}$ & $\begin{array}{l}\text { Records from cluster } 1=10 \\
\text { Records from cluster } 2=0 \\
\text { Records from cluster } 3=0 \\
\text { Records from cluster } 4=0\end{array}$ & $\begin{array}{l}\text { Records from cluster } 1=16 \\
\text { Records from cluster } 2=0 \\
\text { Records from cluster } 3=0 \\
\text { Records from cluster } 4=0\end{array}$ & $\begin{array}{l}\text { Records from cluster } 1=14 \\
\text { Records from cluster } 2=0 \\
\text { Records from cluster } 3=0 \\
\text { Records from cluster } 4=0\end{array}$ \\
\hline $\begin{array}{l}\text { Cluster } 2 \\
\text { Contains }\end{array}$ & $\begin{array}{l}\text { Records from cluster } 1=0 \\
\text { Records from cluster } 2=23 \\
\text { Records from cluster } 3=0 \\
\text { Records from cluster } 4=0\end{array}$ & $\begin{array}{l}\text { Records from cluster } 1=0 \\
\text { Records from cluster } 2=6 \\
\text { Records from cluster } 3=0 \\
\text { Records from cluster } 4=0\end{array}$ & $\begin{array}{l}\text { Records from cluster } 1=0 \\
\text { Records from cluster } 2=11 \\
\text { Records from cluster } 3=0 \\
\text { Records from cluster } 4=0\end{array}$ \\
\hline
\end{tabular}




\begin{tabular}{|c|c|c|c|}
\hline $\begin{array}{l}\text { Cluster } 3 \\
\text { Contains }\end{array}$ & $\begin{array}{l}\text { Records from cluster } 1=0 \\
\text { Records from cluster } 2=1 \\
\text { Records from cluster } 3=10 \\
\text { Records from cluster } 4=0\end{array}$ & $\begin{array}{l}\text { Records from cluster } 1=2 \\
\text { Records from cluster } 2=0 \\
\text { Records from cluster } 3=18 \\
\text { Records from cluster } 4=0\end{array}$ & $\begin{array}{l}\text { Records from cluster } 1=0 \\
\text { Records from cluster } 2=0 \\
\text { Records from cluster } 3=13 \\
\text { Records from cluster } 4=0\end{array}$ \\
\hline $\begin{array}{l}\text { Cluster } 4 \\
\text { Contains }\end{array}$ & $\begin{array}{l}\text { Records from cluster } 1=0 \\
\text { Records from cluster } 2=0 \\
\text { Records from cluster } 3=0 \\
\text { Records from cluster } 2=10\end{array}$ & $\begin{array}{l}\text { Records from cluster } 1=0 \\
\text { Records from cluster } 2=0 \\
\text { Records from cluster } 3=0 \\
\text { Records from cluster } 4=12\end{array}$ & $\begin{array}{l}\text { Records from cluster } 1=0 \\
\text { Records from cluster } 2=0 \\
\text { Records from cluster } 3=0 \\
\text { Records from cluster } 4=16\end{array}$ \\
\hline Correctness & $\begin{array}{l}\text { Cluster } 1=100 \% \\
\text { Cluster } 2=100 \% \\
\text { Cluster } 3=90.9 \% \\
\text { Cluster } 4=100 \%\end{array}$ & $\begin{array}{l}\text { Cluster } 1=100 \% \\
\text { Cluster } 2=100 \% \\
\text { Cluster } 3=90 \% \\
\text { Cluster } 4=100 \%\end{array}$ & $\begin{array}{l}\text { Cluster } 1=100 \% \\
\text { Cluster } 2=100 \% \\
\text { Cluster } 3=100 \% \\
\text { Cluster } 4=100 \%\end{array}$ \\
\hline
\end{tabular}

\section{CONCLUSION}

In clustering algorithms, distance metric plays significant role. For a given dataset, choice of correct distance metric is an exigent task. In this research, study is carried out to analyze the student's interest in use of programming tools, social networking, internet surfing for casual usage and e-learning activities for course studies. In this paper, the impact of three distance metrics viz. Euclidean, Manhattan and Pearson correlation coefficient on two different clustering algorithms namely K-means and Fuzzy c-means clustering were investigated. Distance based similarity measures are generally used in clustering and Euclidean distance in particular. Kmeans clustering with Euclidian distance is popularly used combination. Distance metrics are not always proving as a good option. It does not perform well to capture correlations among the data objects. Through this experiment, the impact of distance metrics on clustering algorithms is analyzed. It is observed that Pearson correlation coefficient metric forms more coherent clusters. With this study, it is concluded that the Pearson correlation coefficient works better than Euclidean distance and Manhattan distance metrics. This study helps the researchers to analyze the impact of distance metrics on clustering algorithms and to take decision about preference of metric for clustering.

\section{REFERENCES}

[1] K. D. Aha, D. and M. K. Albert, "Instance-based learning algorithms,”Machine Learning, vol. 6, pp. 37-66, 1991.

[2] R. D. Short and K. Fukunaga, "A new nearest neighbor distance measure," Proc. of the $5^{\text {th }}$ IEEE Conf. on Pattern Recognition, pp. 81-86, 1990.

[3] T. Daniel and T. E. Daniel, "Making the nearest neighbor meaningful," Proc. of Workshop on Clustering High Dimensional Data and its Applications, 2002.

[4] R. Xu and D. Wunsch, "Survey of clustering algorithms," IEEE Transaction Neural Networks, vol. 16, no. 3, pp. 645- 678 , 2005.

[5] Chaoqun Li and Hongwei Li, "A Survey of Distance Metrics for Nominal Attributes,” Journal of Software, vol. 5, no. 11, pp. 1262-1269, 2010.

[6] Chaoqun Li, Hongwei Li, "Selective Value Difference Metric,”Journal of Computers, vol. 8, no. 9,. pp. 2232-2238, 2013.
[7] Peter Grabusts "The choice of metrics for clustering algorithms," $8{ }^{\text {th }}$ International Scientific and Practical Conference, vol.2, 2011.

[8] Kumar V., Chhabra J.K., Kumar D., "Impact of distance measures on the performance of clustering algorithms," Intelligent Computing, Networking, and Informatics, Advances in Intelligent Systems and Computing, vol. 243, Springer, 2014.

[9] Anil Kumar Patidar , Jitendra Agrawal , Nishchol Mishra, "Analysis of different similarity measure functions and their impacts on shared nearest neighbor clustering approach," International Journal of Computer Applications, vol. no.16, 2012.

[10] Jasmine Irani, Nitin Pise and Madhura Phatak, "Clustering techniques and the similarity measures used in clustering: a survey," International Journal of Computer Applications vol.134, no. 7, pp. 9-14, 2016.

[11] J. Han and M. Kamber, Data mining: concepts and techniques, second edition, San Francisco, CA, USA: Morgan Kaufmann; Boston, MA,USA: Elsevier, 2006.

[12] Anil K.Jain, "Data clustering: 50 years beyond k-means," Pattern Recognition Letters, vol. 31, no.8, pp. 651-666, 2010.

[13] Ali, Ameer M., Karmakar, Gour C. and Dooley, Laurence S., "Review on fuzzy clustering algorithms,"Journal of Advanced Computations, vol.2, no.3, pp. 169-181, 2008.

[14] Yinghua Lu, TinghuaiMa, Changhong Yin, Xiaoyu Xie, Wei Tian and ShuiMing Zhong, "Implementation of the fuzzy cmeans clustering algorithm in meteorological data," International Journal of Database Theory and Application vol.6, no.6, pp.1-18, 2013.

[15] Nikhil R. Pal, Kuhu Pal, James M. Keller, and James C. Bezdek, “A Possibilistic fuzzy c-means clustering algorithm," IEEE Transactions on Fuzzy Systems, vol.13, no. 4, pp.517-530, 2005.

[16] Yung-Shen Lin, Jung-Yi Jiang and Shie-Jue Lee, "A Similarity measure for text classification and clustering,"'IEEE Transactions on Knowledge and Data Engineering, 2014.

[17] I. M. Hanafy, A. A. Salama, K. M. Mahfouz, "Correlation Coefficients of Neutrosophic Sets by Centroid Method," International Journal of Probability and Statistics, vol. 2, no.1, pp.9-12. 2013.

[18] V. P. Mahatme, K. K. Bhoyar, "Data Mining with Fuzzy Method Towards Intelligent Questions Categorization in E-Learning," $8^{\text {th }}$ International Conference on Computational Intelligence and Communication Networks, pp. 682-687, 2016.

[19] V. P. Mahatme, K. K. Bhoyar, "Questions Categorization in ELearning Environment using Data Mining Technique,’International Journal of Computer, Electrical, Automation, Control and Information Engineering, vol.10, no.1, pp.93-97, 2016. 